\title{
Analyzing Problem-Causing Factors for Pakistani EFL Learners in Translating Present Indefinite and Past Indefinite Tenses From Urdu Into English
}

\author{
Muhammad $\operatorname{Din}^{1} \&$ Mamuna Ghani ${ }^{1}$ \\ ${ }^{1}$ Department of English, Islamia University Bahawalpur, Pakistan \\ Correspondence: Muhammad Din, Department of English, Islamia University Bahawalpur, Pakistan.
}

Received: March 9, 2019 Accepted: April 23, 2019 Online Published: April 25, 2019

doi: 10.5539/elt.v12n5p194 URL: https://doi.org/10.5539/elt.v12n5p194

\begin{abstract}
Translation is considered one of the most important skills in studying and learning a language. It is termed as a craft which is thought to be enjoyed by those who aspire to grab a sound command over second language. This study has strived to analyze problem-causing factors faced by the EFL learners in translation particularly in translating present indefinite and past indefinite tenses from Urdu into English and present some suggestions to remedy the problems brought to light by the present study. The present study is quantitative in its approach. The subjects $(\mathrm{n}=200)$ of this study are the students of B.Sc. $\left(4^{\text {th }}\right.$ Year) class. In order to achieve the set objectives of the study, the researcher has conducted an achievement test to achieve the set objectives of the study. The test was comprised of such ten (10) sentences of Urdu of which five were of present indefinite and the remaining five were of past indefinite tense. These sentences were taken from the paragraphs which were selected from the past papers of the university (Bahauddin Zakaria University Multan, Pakistan) examinations. This study has also aimed to present some suggestions as remedial measures to remedy these factors which cause problems for the Pakistani EFL learners in translating present indefinite and past indefinite tenses from Urdu into English. The present study recommends that two forms (singular/plural) of the first form of a verb should be given in the first column instead of infinitival meaning of this form, the exact Urdu meaning of this form of should be given and the grammar books should also give the meaning of the past form of a verb.
\end{abstract}

Keywords: EFL learners, language, tenses, translation

\section{Introduction}

Translation is considered one of the most important skills in studying and learning a language. It is termed as a craft which is thought to be enjoyed by those who aspire to grab a sound command over second language. Translation is also such an intellectual task in which meaning from one language (Source Language) are transformed to another language (Target Language) by following some lexical, grammatical, contextual, cultural and syntactical constraints. Nida (1963) styles translation a message which is naturally equivalent of the source language reproduced in the receptor language. The most important requisite for a good translation is the translator's competence of source language (SL) and target language (TL). Jackson (2005) opines that grammar is of prime significance for translating a source language into a target language. It also involves set of rules, principles, conventions and their exceptions which must be internalized by a translator. Shakur (2008) believes that for translation activity language competence is inevitable and this demands bilingual learning and competence. Such a competence necessitates the sound knowledge of the linguistic systems of the source language (SL) and target language (TL). According to Shakur (2008), translation also involves the development of three different kinds of competence on the part of the translator. They include language competence, subject competence and transfer competence.

\subsection{Significance of English in Pakistan}

English has become an international language or an "international lingua franca". It has achieved such a status as is recognized by every country across the world. Yano (2001) finds a relation between globalization and the rise of English as a global language. Joseph (2004) also seconds this opinion regarding the global recognition of English language. Bozzini (2001) styles English an international language of remarkable sweep and diversity. Han (2005) also attributes the global significance of English language to the EFL learners' mounting awareness 
of the diverse cultures. Crystal (2003) claims English language is taught as a foreign language in more than one hundred countries. Moreover, in most of the countries, this language is used as an official or a "semi-official" language today. In Pakistan, English occupies a place of honor and prestige among the languages spoken here. In recent times, owing to the remarkable success of the English-speaking nations in the fields of industry and politics, the people, governments, and institutions have steered their focus and interest towards this language. Same is the case in Pakistan. It has generally been observed that strong language competence renders students good pedestal and they get entry into higher institutions as the learning of English language wields so much intense importance in Pakistan in the present scenario. English has also become the symbol of education and an elite status in the Pakistani society and has become the language of media, science, technology and a means of inter-national as well as intra-national communication. Ghani (2003) styles this language "a gateway to success" in Pakistan. Akram \& Mehmood (2007) have analyzed the factors which motivate the Pakistani students to go for the learning of English language. They claim that the motivational factors like studies abroad, greater job opportunities, social or missionary aspirations, better economic prospects and academic ends make them learn this language.

\subsection{Teaching of English as a Second/Foreign Language in Pakistan}

English is a compulsory subject up to graduation level in Pakistan, but it has been observed that even after spending a lot of time in learning English, majority of school and college students are unable to write grammatically correct English. It has been observed that the teaching of English in Pakistan, specifically in state-run schools and colleges, is highly ritualized. Seldom do the students focus on learning English when they are mentally obsessed in learning texts for the sake of its reproduction. The reproduction of set texts and the provision of memorized written answers to questions about those texts mean that the teaching of English neglects speaking, listening and critical reading which are termed as the integral features of language competence. Akram and Mehmood (2007) have also analyzed and enumerated some of the problems and challenges which are being faced in teaching English as a foreign language in Pakistan. A very pertinent and relevant issue regarding the teaching of English as a foreign language in Pakistan has been raised by them is that of medium i.e. literature. They seem to be convinced that this medium of teaching English language is inadequate to impart the required competence among the learners of this language. The methodology adopted by the teachers is grammar translation which is another issue acting as an obstacle for the ESL learners to grab competence in the target language. Mostly, English into Urdu translation is resorted to by second language (SL) educators.

\subsection{Urdu Into English Translation - A Pedagogic Resource in Pakistan}

Urdu into English translation is the question which is the most challenging one for most of the ESL learners of every level as this question is given a reasonable proportion in a question paper set by the school/college or board/university examinations so that the ESL/EFL learners can use translation to assimilate L2 information through L1 processing. This question is included in the examination papers to test the various aspects of the ESL/EFL learners' language competence. Shakur (2008) claims translation develops the learners' competence in source and target languages automatically. The development of thoughtful and critical reading is eminently ensured through translation. The researcher also believes that translation is a language learning tool as it ensures the improvement of verbal agility, expansion of learners' vocabulary in L2, consolidation of L2 structures and monitoring and comprehension of $\mathrm{L} 2$.

\subsection{Statement of the Problem}

The problem that the present study aims to cope with is to highlight those factors which cause problems for the Pakistani EFL learners in their translating simple present (Present Indefinite) tense and simple past (Past Indefinite) tense from Urdu into English.

Baker (1992) ascribes the problems in translation to the absence of equivalence between SL into TL. Ervin and Bower (1953) also point out that the differences in syntactic features, meanings of words and cultural contexts pose linguistic challenges to the translators.

\subsection{Objectives of the Study}

- To explore and analyze the factors which cause problems for the EFL learners in translating present indefinite and past indefinite tenses from Urdu into English.

- To present some suggestions to remedy the factors which cause problems for the EFL learners in translating present indefinite and past indefinite tenses from Urdu into English. 


\subsection{Research Questions}

- What factors do cause problems for the EFL learners in translating present indefinite and past indefinite tenses from Urdu into English?

- What suggestions are made to remedy the factors brought to light by the present study?

\section{Literature Review}

Translation is "an inter-language process" as it involves the transference process and the interpretation of the verbal symbols of one language to those of another (Bell, 1991). Alfaori (2017) styles translation multidimensional because the dimensions like process and product mark this abstract concept of this subject field. So, reliability and validity are the glaring features of translation. Catford (1965) also brands translation "an operation performed on language" because of the substitution of a text from one language to the text of another.A good and accepted translation requires a translator to be equipped with the skills to represent the whole scheme of ideas, express manner and style, bring ease and render an identical response of a given text (Nida, 1964; Tytler, 1907). Vinay and Darbelnet (1995) also lay stress on replicating the original situation of a given text (source language) by using different words. The presents study aims to unearth the problems faced by Pakistani EFL learners in translating present indefinite and past indefinite tenses from Urdu into English. In this respect, the researcher has reviewed the literature relating this field and this has been discussed as follows;

Buriro et al. (2016) have analyzed Sindhi EFL learners' errors in translation Sindhi into English. They have administered a test consisting of ten Sindhi sentences to twenty undergraduate students to translate them into English. The researchers have used "a modified model of error analysis propounded by Rod Ellis (1994)" for the analysis of these errors. The findings of this study reveal that L1 interference, poor knowledge of grammar and learners' assumptions are the factors which are responsible for their poor translation skills. They also argue that these learners have committed spelling, morphological and punctuation errors because of their L1 interference.

Koshhal (2017) has conducted a study to investigate the errors committed by the Iranian EFL elementary learners in translating Persian sentences into English. The researcher has analyzed these errors by categorizing them into three aspects i.e. spelling, grammar and choice of words. The results of this study show that these EFL learners committed a variety of errors. For instance, these errors were relating to the wrong use of the parts of speech, tenses and their sequence, word order, articles, voice, negative imperatives and change of narration. This study also throws light on the sources of these errors committed by the participants of this study. According to Khoshhal (2017), there are three main sources of these errors. They include the errors caused by first language of the EFL learners, over generalization of specific grammatical rules and poor teaching techniques. The researcher rounds off his discussion by claiming that the teaching of verbs should be more focused as this area proves to be formidable challenge for EFL learners in translating source language into target language. To this end, Khoshhal (2017) recommends that teachers should present maximum examples and instances of the use of verb in the process of translation to the students so that they may get familiarize themselves with the correct use of the form of verbs in translation. Ngangbam (2016) has conducted a case study regarding the errors committed by English language learners of Mutah University. The researcher has categorized the errors committed by the subjects of this study into fifteen categories to find the causes and frequency of these errors. The results of this study reveal that mother tongue (MT) interference, lack of grammatical knowledge, wrong sentence fragmentation and overuse are among those factors which cause problems for the English learners of this university.

Baker (1992) argues that "grammatical equivalence" is one of the problems that students face in doing translation because grammatical rules vary from language to language. The differences of grammatical structures cause problems demand the required changes in transferring text from source language to target language. This can be done by adding or omitting some information in target language. In this regard, Baker (1992) maintains that a translator must be well-versed with those grammatical devices which can be resorted to in translating source language into target language. Such grammatical devices include tense and aspect, number, gender, person and voice.

In translation theory, equivalence enjoys paramount importance. Much effort has been exerted by theorists to investigate the effect of this notion on a translator while dealing with a text in the process of translation (Alfaori, 2017, p. 86). According to Alfaori (2017), a translator must comprehend the meanings of a text given in source language, take care of the loss of meaning in translating SL into TL and avoid non-equivalence and poor substitutes. According to Birjandi (1999), lexical knowledge and the conceptual understanding of a text on the part of a translator may flourish his/her translation skills. This researcher has reached these findings by exploring the effects of the EFL learners' lexical knowledge on their translation skills. 
Tandikombong et al. (2016) have conducted a study to identify the grammatical errors made by the Indonesian students in translating Indonesian text into English text. They have found out the students have made various types of errors while doing translation. But the most frequent errors were of verb (39.16\%) followed by noun errors. Their study has also made probe into the factors which cause errors in translating Indonesian text into English text. For instance, ignorance of rule restriction, overgeneralization, application of rules and false concept hypothesized are the factors which cause problem for the Indonesian translators in rendering Indonesian text into English text.

Alfadly and Aldeibani (2013) have analyzed those linguistic problems which the Yemeni English Majors at Hardamout University have to face in translation between Arabic and English. Alfadly and Aldeibani (2013) have found out that mistranslation is one the problems which is caused because of the learners' weakness in grammar. Incorrect passives, L1 interference and the use of participle are those linguistic problems which have been brought to light by Alfadly and Aldeibani (2013). Kern (1994) terms translation a cognitive strategy in the process of reading comprehension. He points out the students go for translation to comprehend text. Cook (1992) has also maintained that ESL learners resort to their first language during their processing the second the language.

Kasmer (1999) highlights the importance and role of translation in an ESL/EFL classroom and throws light on the approaches for using translation in this context. While discussing the pay offs of bilingual immersion, Kasmer (1999) maintains that ESL/EFL learners can comprehend the main ideas of a text through bilingual immersion. Another advantage that can be reaped through bilingual immersion is the assimilation of foreign culture tagged with a foreign language. Co-teaching is another approach which can be used in an ESL/EFL classroom. The researcher claims that the ESL/EFL learners can make use of the grammar of both native and target language through co-teaching. This approach can also ensure the facilitation of guided negotiation of meaning. Apart from this, co-teaching helps the ESL/EFL learners in learning sentence structure through consciousness raising which alleviates some forms of culture shocks. According to Kasmer (1999), the use of bilingual text in an ESL/EFL classroom can also be helpful for the learners. Even the use of combination approaches is also very advantageous for the ESL/EFL learners. Kasmer (1999) also suggests some translation techniques and approaches to be adopted in ESL/EFL classrooms. For instance, lost in the translation, role-plays with native language brainstorming and bilingual dialogues are such translation approaches as can benefit the $\mathrm{ESL} / \mathrm{EFL}$ learners in various ways.

Jawaid and Zeman (2011) believe that translation becomes a complex task because of the linguistic differences between source and target languages. Talking with specific reference to Urdu and English languages, the researchers maintain that in Urdu language Verbs inflect according to number, gender and the head noun as Urdu is highly inflectional and diverse in morphology as compared with English. Shakur (2008) throws light on the significance of translation by claiming that it develops the ESL/EFL learners' communicative strategies and skills. It also enhances the learners' oral fluency and the creative use of foreign language. The researcher further maintains that the qualities like accuracy, clarity and flexibility which are essential to language learning can be ascertained through translation.Alsobhani and Muthanna (2011) maintain that there are multifaceted problems the EFL learners of Yemen face in translating Arabic into English. According to them, the lack of the practice of grammar and its inadequate knowledge, inadequate lexical resources, teaching methodology and environment and insufficient cultural background are the problems faced by these EFL learners in translating Arabic into English. The selection of an appropriate lexical item is also one of the challenges the Yemeni EFL learners encounter in translating source language into target language.

The review of studies carried out in the field of translation particularly with reference to the problems faced by the EFL learners brings the fact to light that there is still a gap that should be dealt with. The studies that have been reviewed reveal that researchers have conducted studies in their contexts relating the general areas which pose problems for EFL learners. The present study has been carried out to unearth the problems faced by the Pakistani EFL learners in translating Urdu into English particularly present indefinite and past indefinite tenses.

\section{Research Methodology}

The present quantitative study aims to investigate the problems faced by the EFL learners in translating Urdu into English particularly present indefinite and past indefinite. An achievement test has been developed to achieve the set objectives of the study.

\subsection{Population of the Study}

The population of the present study comprises all the male and female graduation students (university students) of Punjab (Pakistan). 


\subsection{Sample of the Study}

The present study has gone for one of "probability sampling" which is reasonably representative sample using resource. Dornyei (2011) maintains that the key component of probability sampling is "random sampling method". The assumption underlying this procedure is that this procedure minimizes the effects of any extraneous or subjective factors. Thus, random samples are always more representative than non-random samples (Dornyei, 2011). Moreover, Gay et al. (2012) also claim that random sampling is the best way to obtain a representative sample as random sampling is required for many statistical analyses. These analyses permit the researcher to make inferences about a population based on the behavior of a sample. The students $(n=200)$ of B.Sc. $\left(4^{\text {th }}\right.$ Year $)$ class are the sample of this study.

\subsection{Profile of the Sample}

The sample of this study are the students of $4^{\text {th }}$ Year class. These student study science subjects in different combinationswhich have been recommended by the relevant University. All the subjects of this study are from Government colleges of the province of Punjab (Pakistan). They study the subject of English as a compulsory subject for 100 marks. Out of these 100 marks, they are to attempt a question of Urdu into English translation for 20 marks. This question poses a challenge for these EFL learners as they generally opt an optional question of Letter Writing in lieu of translation.

\subsection{Research Instrument}

An achievement test was developed as a research instrument and conducted by the researcher to achieve the set objectives of the study. The test was comprised of such ten (10) Urdusentences of which five were of present indefinite and five were of past indefinite tense. These sentences were taken from those paragraphs which were selected from the past papers from 2007 to 2017 Annual Examinationof the university (Bahauddin Zakaria University Multan, Pakistan) examinations. The selection of these items for the development of this achievement test was made keeping in view the objectives of the study.

The reason behind the choice of these paragraphs from the university exam was that the university papers come up to the standards of reliability and validity of any achievement test as these papers are made by keeping in view the average, good and excellent students in view. After pooling these items for the development of the achievement test, the researcher presented this test to two experts to seek their expert opinion and feedback for its content and face validity. The researcher also discussed with theme certain issues in the development process of this instrument. The changes which were recommended by these experts were incorporated before setting this tool into application.

\subsection{Limitations of the Study}

The present study chiefly aims to discuss the Pakistani EFL learners' problems with reference to the translation of present indefinite and past indefinite tenses from Urdu into English and highlight those factors which pose challenges to them. The participants of this study are the university students of the state-run government colleges of Pakistan. These things constitute the limitations of this study.

\subsection{Ethical Considerations}

All the ethical considerations were kept in view during the data collection, data analysis and reporting phases of the study. Complete anonymity and confidentiality of the respondents was ensured by assigning them codes in reporting their views. Also, before collecting the responses, a consent form was got duly signed from the head of the institutions and class teachers from where the data was collected.

\section{Results}

This study aims to highlight the the factors which cause problems for the EFL learners in translation particularly in translating present indefinite and past indefinite tenses from Urdu into English. Apart from this, there are also many problems which the Pakistani EFL learners face in translating Urdu into English. These problems are relating to the wrong use of pronouns, articles, conjunctions, punctuation, inappropriate lexical items marks and subject omission, sentence fragmentation, confusion regarding the difference between adjective and adverb. As the main thrust of this study is the problems faced by EFL learners' in translating present indefinite and past indefinite tenses from Urdu into English, so the problems mentioned above have not been discussed in detail here.

Apart from the general problems mentioned above, this study has chiefly focused on highlighting those factors which cause problems for EFL learners in translating present indefinite and past indefinite tenses from Urdu into English. The instances of incorrect translation of these two tenses from Urdu into English along with their 
frequency and percentage have been presented in a table given as follows;

Table 2. Instances of incorrect (English) translation of present indefinite and past indefinite tenses from Urdu into English

\begin{tabular}{|c|c|c|c|}
\hline S. No. & Translation (Incorrect) & Frequency & Percentage \\
\hline 1 & We are become happy by calling others bad. & 44 & 22 \\
\hline 2 & We are not takeourselves by the collar. & 39 & 19.5 \\
\hline 3 & Natural beauty is provide the people happiness. & 25 & 12.5 \\
\hline 4 & $\begin{array}{l}\text { The attraction and charms of the beautiful things is } \\
\text { increase with the passage of time. }\end{array}$ & 53 & 26.5 \\
\hline 5 & $\begin{array}{l}\text { The Process of education is progress with the mutual } \\
\text { cooperation of teacher and student. }\end{array}$ & 41 & 20.5 \\
\hline 6 & $\begin{array}{l}\text { Our forefathers were earn their livelihood diligently and } \\
\text { were live simple life. }\end{array}$ & 36 & 18 \\
\hline 7 & $\begin{array}{l}\text { Man was not know much about mathematics, space } \\
\text { research, engineering, trade, banking, communication and } \\
\text { electronics before the invention of computer. }\end{array}$ & 57 & 28.5 \\
\hline 8 & $\begin{array}{l}\text { Astrology and fortune telling were affect the lives of the } \\
\text { people very much. }\end{array}$ & 33 & 16.5 \\
\hline 9 & $\begin{array}{l}\text { In the past, the people were bring drinking water from } \\
\text { miles. }\end{array}$ & 21 & 10.5 \\
\hline 10 & $\begin{array}{l}\text { The people were respect each other and were shareeach } \\
\text { other's sufferings. }\end{array}$ & 49 & 24.5 \\
\hline
\end{tabular}

Table 2 shows how the Pakistani EFL learners face problems in translating simple present (present indefinite) tense and simple past (past indefinite) tense from Urdu (SL) into English (TL). For instance, a sentence which was of present indefinite tense was translated by the subjects into English as follows:

دوسرون كو برا ك, كريم خوش هو جانـــي.

\section{Translation:}

We are become happy by calling others bad. (Incorrect)

\section{Transliteration:}

doosrun ko burakehkar hum khush ho jate hein.

Gloss: others to bad calling by we become happy

In the same way, another sentence which was of past indefinite was translated by the students into English as follows:

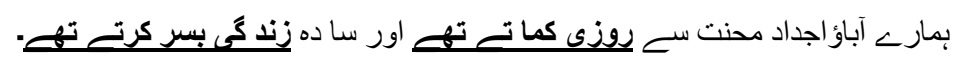

\section{Translation:}

Our forefathers were earn their livelihood diligently and were live simple life. (Incorrect)

\section{Transliteration:}

hamarey abaao ajdad mehnat se roozi kamate thei aur sadha zindagi basar kartey thei

Gloss: our forefathers hardwork with livelihood earned and simple life lived

The above given examples showthat the Pakistani EFL learners remain unable to translate the verbs of present indefinite and past indefinite from Urdu into English. They are misled by the concept that the last two word of a Urdu sentence having Present Indefinite and Past Indefinite tenses like "هو جا تخ and "روزى كما تــنه (rouzi kmətei thei) would be translated into English with the help of two different verbs. That's why they go for the expressions like "are become" and "were earned". 


\section{Discussion}

The objectives set by the present study are to explore analyze the factors which cause problems for the EFL learners in translating present indefinite and past indefinite tenses from Urdu into English and to present some suggestions to remedy the factors which cause problems for the EFL learners in translating present indefinite and past indefinite tenses from Urdu into English. So, the researcher has discussed these issues as follows;

The first objective of the present study is to explore the factors which cause problems for the Pakistani ESL learners in translating present indefinite and past indefinite tenses from Urdu into English. This study has brought to light some factors which have been discussed as follows;

\subsection{L1 Interference}

The present study has found out that L1 interference is one of the major factors which make the Pakistani EFL learners to add auxiliary verbs in translating present indefinite and past indefinite tenses from Urdu into English. This is so because they fail to apply grammatical devices in translating source language into target language because of the lack of the knowledge of grammatical equivalence. The findings of the study conducted by Khoshhal (2017) also corroborate the findings of the present study. Koshhal (2017) has also strived to trace the causes and factors of errors in translating Persian sentences into English. According to the results of this study, there are three types of factors which cause the errors in translation carried out by the Iranian EFL learners. These factors include first language interference (interlingual errors), over generalization of grammatical rules (intralingual errors) and poor teaching techniques. Kim (1998) also seconds the findings of the present study that errors committed by EFL learners in translating source language into target language are caused by L1 transfer. According to the results of the study conducted by Kim (1998), 22\% of the errors are attributed to L1 transfer. Likewise, Kushhal (2017) maintains that in a study conducted in the Korean context, it has been found out that $24 \%$ of the errors were caused because of the transfer of the structures of L1 when the Korean EFL learners were asked to translate Korean sentences into English. In the same vein, Jdetawy (2011) has also highlighted the issue that sometimes "interlingual transfer strategy" poses problem for the Arab EFL learners in their attempt to learn second language. The findings of the study carried out by Sarfraz (2011) also second the findings of the present study as this study shows that $46.36 \%$ of the errors committed by the Pakistani EFL learners have been caused by interlanguage process while $11.4 \%$ errors are the result of mother tongue (MT) interference. The findings of the case study carried out by Ngangbam(2016) also substantiate the findings of the present study that L1 interference is the factor which poses challenges to EFL learners in translating and interpreting second language. The findings of the studies conducted by Kambal (1980), Kao (1999) and Lin (2002) also second the findings of the present study that EFL learners encounter difficulties in empowering L2 because of this factor. Buriro et al. (2015) have also reached the findings that L1 interference causes problems in translating Sindhi language into English by the Pakistani EFL learners. According to their study, $45 \%$ of the errors are related to L1 interference. In fact, they ascribe all the errors to the EFL learners' L1 interference.

\subsection{Infinitival Meaning}

The second factor which causes problem for the Pakistani EFL learners in translating present indefinite and past indefinite tenses from Urdu into English is the grammar books which are used to teach translation at every level. For instance, when the Pakistani EFL learners are taught English verbs, they are almost always taught only three forms of a verb i.e. present, past and past participle. The grammar books published by the Punjab Text Book Board, Pakistan give these three forms of a verb. For instance, verb "become" is presented in these books as follows;

$\begin{array}{ccc}\text { Present } & \text { Past } & \text { Past Participle } \\ \text { Become } & \text { became } & \text { become }\end{array}$

Here, the verb "become" is given the meaning in Urdu as "هونا"(həunə) which is an infinitive (tense less)and it means "tobe". When the Pakistani ESL learners translate an expression like "هو جان ته "هين"(həu d3atei hein), they translate it as "are become" because the grammar books present the present form of verb tense less. This thing misleads the translators to translate an Urdu sentence of present indefinite into English by adding an auxiliary verb like "are" to strike an agreement between subject and verb as they remain unable to the know the complete meaning of a verb like "become" which embodies the meaning of present tense. That's why, these ESL learners translate the Urdu expressions "هو جا ته هيu" (həu d3atei hein) into English on the premise that the English equivalence for "هو جاته" (həu d3atei)is "become" and for "هين" (hein)is "are”.

Thus, these EFL learners remain unable to comprehend the meaning of the present form of verbsgiven in a grammar book. The meanings of present form of a verb include the aspects which have been given as follows; 
a) Plural form of verb

b) Present form of verb is an equivalent for such Urdu expressions as end with an auxiliary verb and needs no auxiliary verb to maintain subject-verb agreement.

The problem that the ESL learners face in translating past indefinite tense from Urdu into English is because they remain unable to comprehend the full meaning of the past form of a verb. For instance, the Urdu expression تناثر "كرتخ ته "(m3tasa kərtei thei) was translated by 16.5\%of the subjects of the present study as "were affect" because the ESL learners remain unable to know that inEnglish, unlike Urdu, the past form of a verb carries the meaning of an action/state and tense as well. This also causes the ESL learners to mistranslate the Urdu expressions like " ضا فئ هو تا هـ" (aひzafə həuta hei) into "is increase". The reason is that most of the ESL learners consider these Urdu expressions as two separate words and they try to use two different words as their equivalents in English for they are not generally taught that only the past form of a verb suffices for such expressions. For example, the past form of the verb "go" is "went" which is always plural and not require any auxiliary verb. But the students use singular or plural auxiliary verb (was/were) along with this form of verb. This problem can be attributed to the teaching techniques which are faulty and poor and do not let the EFL learners to have exposure to maximum and variety of instances of the use of the correct form of the verbs. Owing to this, students commit errors in rendering Urdu sentences into English.

The present study finds that the Pakistani EFL learners remain unable to comprehend the meaning of the present and past forms of a verb in English language and thus they try to add an extra auxiliary verb when they go for translating present indefinite and past indefinite tenses from Urdu into English. This shows that face the problem of finding the exact grammatical equivalence in the process of translation. The findings of the study conducted by Alsobhani and Muthanna (2011) also reveal that the Arabic EFL learners face problems in translating SL into TL because of the lack of the practice of grammar. This results in their being unable to find a grammatically appropriate lexical item in translating source language into target language. Zawahreh's (2013) study also lays stress on the EFL learners' paying attention to the parts of speech, context and collocations for getting command over translation skills.

The present study has strived to highlight those factors which problems for the Pakistani EFL learners in translating Urdu into English. The results of this study are corroborated by the results of the study conducted by Khoshhal (2017) in the Iranian context as this study claims that $66 \%$ of the participants of the study have committed the errors relating to the wrong use of verbs and the wrong use of tense while translating Persian sentences into English. The study conducted by Ngangbam (2016) reveals that Mutah university English language learners commit errors of the wrong use of verb because of the lack of grammatical knowledge. According to this study, $3.46 \%$ of the errors are relating to the verbs and $5.06 \%$ of errors are caused because of the syntactic problems faced by the subjects of this study. The findings of the quantitative study conducted by Akhtar and Rizwan (2015) also corroborate the findings of the present study. According to their study, EFL learners frequently commit errors related to tenses and morphemes. This study ascribes these errors to L1 interference.

The findings of the study conducted by Baker (1992) demonstrate that EFL learners remain unable to translate a source language (SL) into target language (TL) when they do not know about the "grammatical equivalence" i.e. tense and aspect involved in the process of translating source language into target language. Apart from this, this study also focuses on the importance of the comprehension of other aspects like gender, person, number and voice in the process of translation. Likewise, the findings of the study conducted by Birjandi (1999) reveal that there lies a significant relationship between EFL learners' translation skills and their lexical knowledge. The present study finds that the Pakistani EFL learners remain unable to comprehend the meaning of the present and past forms of a verb in English language and thus they try to add an extra auxiliary verb when they go for translating present indefinite and past indefinite tenses from Urdu into English. This shows that face the problem of finding the exact grammatical equivalence in the process of translation. The findings of the study conducted by Alsobhani and Muthanna (2011) also reveal that the Arabic EFL learners face problems in translating SL into TL because of the lack of the practice of grammar. This results in their being unable to find a grammatically appropriate lexical item in translating source language into target language. Zawahreh's (2013) study also lays stress on the EFL learners' paying attention to the parts of speech, context and collocations for getting command over translation skills.

\section{Conclusion}

This study has strived to unearth and highlight the factors which cause problems for the Pakistani EFL learners in translating Urdu into English particularly present indefinite and past indefinite tenses. It has been found out 
that these learners commit errors in translating these two tenses because of the presence of some factors. Among these factors are L1 transfer and interference, lack of grammatical practice, lack of the knowledge of the grammatical equivalence and the use of the poor and outmoded teaching material and old-fashioned techniques. Apart from this, this study has also found that teaching the forms of verbs through grammar books published by the Punjab Textbook Board, Pakistan cause problems for the learners in rendering Urdu into English.

The findings of this study can be very helpful in teaching English as foreign language in Pakistan particularly when Translation is used as a pedagogical resource. This study will have pedagogical implications as it will help;

- Foreign language educators to teach English as foreign language through translation in a better way

- Teachers to examine and revise their teaching techniques for better outcomes

- Syllabus designers in designing syllabus and developing such materials as can prove EFL learners' way for comprehensive EL learning

- Researchers in the field of teaching methodologies so that they may conduct more studies in this area to develop, design and introduce the most modern techniques and methodologies which can be helpful for the EFL learners

- EFL learners particularly the Pakistani EFL learners to develop and enhance their translation skills and abilities

This study has also aimed to present some suggestions as remedial measures for the problems faced by the Pakistani EFL learners in translating present indefinite and past indefinite tenses from Urdu into English. In the light of the findings of the present study, the researcher makes some recommendations which have been given as follows;

- Two forms (singular/plural) of a verb should be given in the first column

- Instead of infinitival meaning of the present form a verb, the exact Urdu meaning of this form of should be given

- The grammar books should also give the meaning of the past form of a verb

- Studies should also be conducted to highlight the effectiveness and usefulness of the bilingual and monolingual dictionaries

\section{References}

Akhtar, S., \& Rizwan, M. (2015). Taxonomy of Syntactic and Morphological Errors in Task-Based Activity of Urdu-English Translation Based on Error Analysis and Contrastive Analysis. European Academic Research, 2(10), 13505-13525.

Alfadly \& Aldeibani. (2013). An Analysis of Some Linguistic Problems in Translation between Arabic and English Faced by Yemeni English Majors at Hadramout University. Journal of Islamic and Human Advanced Research, 3(1), 5-26.

Alfaori, N. A. D. M. (2017). Equivalence Problems in Translation. Sino-US English Teaching, 14(2), 86-97. https://doi.org/10.17265/1539-8072/2017.02.003

Al-Saeed, M. S. (1989). Major Problems in Translating Quranic Meaning into English (Unpublished Doctoral Dissertation, Yarmouk University).

Baker, M. (1992). In Other Words: A Course Book on Translation. London and New York: Routledge. https://doi.org/10.4324/9780203327579

Bell, R. T., \& Candlin, C. (1991). Translation and Translating: Theory and Practice. London: Longman.

Birjandi, P. (1999). Lexical Knowledge and Translation Ability. Journal of Education and Practice, 2, 1-8.

Buriro et al. (2015). An Error Analysis of Undergraduate Learners' Sindhi-English Translation. Asianet-Pakistan.

Catford, J. C. (1965). A Linguistic Theory of Translation, An Essay in Applied Linguistics. London: Oxford University Press.

Cook, V. (1992). Evidence for Multicompetence. Language Learning, 42, 557-591. https://doi.org/10.1111/ j.1467-1770.1992.tb01044.x

Gay et al. (2012). Educational Research: Competencies for Analysis and Application. (C) 2012 Pearson.

Dornyei, Z. (2011). Research Methods in Applied Linguistics: Qualitative, Quantitative and Mixed 
Methodologies, Oxford University Press.

Jackson, H. (2005). Good Grammar for Students. Sage Publication London. Thousand Oaks. Delhi.

Jdetawy, L. F. A. (2011). Problems Encountered by Arab EFL Learners, Language in India. Strenth for Today and Bright Hope for Tomorrow, 11(3), 19-27.

Jawaid, B., \& Zeman, D. (2011). Word-order Issues in English-to-Urdu Statistical Machine Translation. The Prague Bulletin of Mathematical Linguistics (PBML), 87-106. https://doi.org/10.2478/v10108-011-0007-0

Kambal, M. O. A. (1980). An Analysis of Khartoum University Students' Composition Errors with Implications for Remedial English in the Context of Arabic Nation (Unpublished, Ph.D. Dissertation University of Texas at Austin).

Kao, C. C. (1999). An Investigation into Lexical, Grammatical and Semantic Errors in English Compositions of College Students in Taiwan. Fu Hsing Kang Journal, 67, 1-32.

Kasmer, W. (1999). The Role of Translation in EFL/ESL Classroom. Module 2, MA TEFL/TESL ODL, University of Birmingham, UK.

Kern, R. G. (1994). The Role of Mental Translation in Second Language Reading. Studies in Second Language Acquisition, 16, 441-461. https://doi.org/10.1017/S0272263100013450

Kim, I. (1988). A Study of Errors and Intelligibility of Korean College Students' Utterances (Unpublished Master's Thesis. Kangwon University, Chuncheon, Korea).

Kushhal, Y. (2017). An Error Analysis Case Study: Out of Context Translation of Persian Sentences into English for Elementary EFL Learners. Educational Process. International Journal, 6(4), 89-100. https://doi.org/10.22521/edupij.2017.64.6

Lin, S. (2002). A Case Study of English Writing Competence of Students at the Mei Ho, Institute of Technology. Journal of Mei Ho Institute of Technology, 20, 180-206.

Ngangbam, H. (2016). An Analysis of Syntactic Errors Committed by Students of English Language Class in the Written Composition of Mutah University: A Case Study. European Journal of English Language, Linguistics and Literature, 3(1), 1-13.

Nida, E. H. (1963). Toward a Science of Translating. New York.

Nida, E. A. (1964). Toward a Science of Translating: With Special Reference to Principles and Procedures Involved in Bible Translating. Netherlands: Brill.

Sarfraz, S. (2011). Error Analysis of the Written English Essays of Pakistani Undergraduate Students: A Case Study. Asian Transactions on Basic \& Applied Sciences, 01(03), 29-51.

Shakur, N. (2008). Constructing Pathways to Translation: A Study in Translation Pedagogy and Process From English into Urdu and Vice Versa, National University Of Modern Languages Islamabad.

Tandikombong et al. (2016). Grammatical Errors in the English Translation Made by the Students of English Study Program of UKT Toraja. ELT Worlwide, 3(1).

Tytler, A. F. (1907). Essay on the Principles of Translation. London: Den.

Vinay, J. P., \& Darbelnet, P. (1995). Comparative Stylistics of French and English: A Methodology for Translation. In J. C. Sager, \& M. J. Hamel (Trans.), Amsterdam/Philadelphia: John Bebjamins. https://doi.org/10.1075/btl.11

\section{Copyrights}

Copyright for this article is retained by the author(s), with first publication rights granted to the journal.

This is an open-access article distributed under the terms and conditions of the Creative Commons Attribution license (http://creativecommons.org/licenses/by/4.0/). 